\title{
Osmoregulation pattern and salinity tolerance of the white shrimp Litopenaeus vannamei (Boone, 1931) during post-embryonic development
}

\author{
Jennyfers Chong-Robles ${ }^{\mathrm{a}}$, Guy Charmantier ${ }^{\mathrm{b}}$, Viviane Boulo ${ }^{\mathrm{b}}$, Joel Lizárraga-Valdéz ${ }^{\mathrm{c}}$, Luis M. \\ Enríquez-Paredes ${ }^{a}$, Ivone Giffard-Mena ${ }^{\mathrm{a}, \text { * }}$
}

\author{
a Universidad Autónoma del Estado de Baja California, Laboratorio de Ecología Molecular, Kilómetro 103 \\ Carretera Tijuana-Ensenada, Ensenada, Baja California, Mexico \\ b Université Montpellier 2, Equipe AEO Adaptation Ecophysiologique et Ontogenèse, UMR 5119, Ecosym, UM2, \\ CNRS, IRD, Ifremer, Place Eugène Bataillon, CC 092, 34095 Montpellier Cedex 05, France \\ ${ }^{\mathrm{C}}$ AQUAPACIFIC, S.A. de C.V., Mazatlán, Sinaloa, Mexico \\ *: Corresponding author : Ivone Giffard-Mena, tel.: + 526461744570 ; email address : igiffard@uabc.edu.mx
}

\begin{abstract}
:
The euryhaline white shrimp Litopenaeus vannamei lives in both coastal and oceanic areas through ontogeny. Its osmoregulation pattern and variations in its tolerance to salinity are partially known from several studies under different experimental conditions (developmental stages, salinities and acclimation procedures). Although $L$. vannamei is recognized as one of the most euryhaline penaeid species, with adults and juveniles exhibiting a hyper-hypo-osmoregulatory pattern and being able to tolerate a wide salinity range, little is known on larval and early postlarval strategies to cope with salinity fluctuations. In order to establish their euryhalinity range and to fully understand the ontogenetic changes in $L$. vannamei osmoregulatory pattern, we evaluated the effect of six salinities $(5,10,20,32,45$ and $60 \mathrm{psu})$ on 17 developmental stages by directly exposing them to experimental salinities and conducting observations during the next $48 \mathrm{~h}$. At $5 \mathrm{~h}$ post-osmotic shock (hps), all developmental stages survived (>20\%) in 20,32 and 45 psu. The euryhalinity and osmoregulation pattern changed at some developmental stages of $L$. vannamei. The hyper-hypo osmoregulatory pattern exhibited by juvenile and adult appears to be established early in the first post-larval stage PL1 (ontogenetic osmoregulation pattern type 3 ), with higher tolerance to salinity variations observed in PL2, PL4 and PL22 suggesting that $L$. vannamei shows a progressive increase in the efficiency of osmoregulatory mechanism following last metamorphosis.
\end{abstract}

\section{Highlights}

- The white shrimp osmotic pressure was established for each developmental stage. $\downarrow$. vannamei osmoregulatory pattern during development is of type 3. Tolerance to salinity increases during postembryonic development.

Keywords: Osmotic pressure ; Hypo-hyper osmoregulation ; Osmotic stress ; Survival ; Crustacean ; Larvae 


\section{Abbreviations}

- hps, hours post-shock osmotic ;

- psu, practical salinity unit ;

- hOP, hemolymph osmotic pressure ;

- wOP, water osmotic pressure ;

- OC, osmoregulatory capacity ;

- FW, freshwater ;

- eu, experimental unit ;

- $\mathrm{S} \%$, survival percentage ;

- $\mathrm{FT}$, fusion temperature ;

- $\mathrm{mOsm} \cdot \mathrm{kg}^{-1}$, milliosmoles/kilogram ;

- IP, isosmotic point 


\section{Introduction}

Salinity fluctuations, as for other environmental factors, triggers organism adaptive responses with an effect on different physiological functions, and ultimately affecting growth and survival (Young et al., 1989). For more than a decade, researchers have been observed the importance of the osmoregulation in species whose ecological distribution pattern suggests different osmoregulatory abilities during ontogeny (Charmantier and Wolcott, 2001). Osmoregulation is a key physiological function and it is an interesting field for understands ecological distribution patterns, with possible applications to improve culture conditions production.

Aquatic crustacean have different osmoregulatory adaptive strategies to maintain their haemolymph according to their surrounding media (Péqueux et al., 2006). Crustaceans osmoregulatory patterns ranges from osmoconformation to hyper and hypo osmoregulation (Charmantier et al., 2009; Péqueux et al., 2006), but during their post-embryonic development they exhibit three ontogenetic osmoregulation patterns: (1) osmoregulation varies little with developmental stage and the adults are often weak regulators or osmoconformers; (2) the adult type of osmoregulation is established in the first post-embryonic stage; (3) metamorphosis marks the appearance of the adult type of osmoregulation (Charmantier, 1998). The quantification of the hemolymph osmotic pressure (hOP) is used to know both the osmoregulation pattern and the Osmoregulatory Capacity (OC: difference between hemolymph and external medium osmolalities) of crustaceans acclimated to different salinities. Measuring OC allows to determine the effect of any environmental variables on the physiology of the animal (Lignot et al., 2000), and to compare osmoregulatory abilities between developmental stages. 
Osmoregulation is energetically costly but necessary in species like penaeid shrimp.

Larvae development occurs in the ocean while postlarvae are recruited into coastal zones (estuaries and lagoons) where they growth up to juveniles and adults (FAO, 2004). Just before recruitment, individuals should have developed their physiological capabilities to overcome the fluctuating nature of those environments (McKenney and Celestial, 1995). Few researches have studied the osmoregulatory pattern, the $\mathrm{OC}$ and the euryhalinity strategies at different developmental stages in penaeid shrimp. It have been evaluated only in the tiger shrimp $P$. japonicus (Charmantier et al., 1988) and more recently in the blue shrimp Litopenaeus stylirostris (Pham et al., 2012b). These species showed a type 3 pattern of osmoregulation during their ontogeny, and increases in OC and in euryhalinity were correlated with the development of epithelia and organs involved in osmoregulation (Charmantier et al., 1988; Pham et al., 2012a).

To date, little attention has been paid on the effect of salinity (including low and high salinity) on survival and its effect on hOP in larval and initial PLs stages of one of the most important penaeid specie, Litopenaeus vannamei. This species like others penaeid shrimps develop through a series of stages during post-embryonic development: from the naupliar stages (N1-6), through three Zoea (Z1-3), three Mysis (M1-2), then several Post-Larvae (PL) turning into Juveniles (J) and Adults (A) (Kitani, 1986).

L. vannamei has a high commercial value, a wide resistance to certain viral pathogens and it is one of the most euryhaline penaeids species, with juveniles and adults tolerating salinities from freshwater (FW) to 50 psu (Castille and Lawrence, 1981; FAO, 2011; Pan et al., 2007). These stages hyper-osmoregulate at salinities below its iso-osmotic point and hypoosmoregulate at higher salinities; the iso-osmotic salinity is close to 25 psu (Bückle et al., 2006; Castille and Lawrence, 1981; Díaz et al., 2001; Rámos-Carreño et al., 2013). Their salinity 
tolerance depends on the range of salinities, on developmental stages and on exposure procedures (direct transfer vs gradual transfer). The tolerance to low salinity (FW to $20 \mathrm{psu}$ ) is known to be acquired progressively, from PL2 to PL20 (Aquacop et al., 1991), but the timing of tolerance to high salinity is unknown. Between PL10 to PL23, and in juvenile and adult the range of survival depends on the combination of salinity with each developmental stage among other variables (Balbi et al., 2005; Esparza-Leal et al., 2010; Jayasankar et al., 2009; Laramore et al., 2001; McGraw et al., 2002; Ponce-Palafox et al., 1997; Sowers et al., 2006; Zhang et al., 2009). The effect of salinity (including low and high salinity) on hOP, and its effect on survival in larval and initial PLs remain unstudied.

The purpose of this study is to describe the eurihalinity and osmoregulation pattern during post-embryonic development of $L$. vannamei (from early larvae to adults). We quantified the OP and survival in six salinities $(5,10,20,45$ and 60 psu, including the traditional culture salinity conditions in a specific hatchery, 32-34 psu). Gradual acclimatization allows physiological adaptation in a less stressful way (Young et al., 1989). But for ontogenetic studies in a species such as L. vannamei, this procedure cannot be used due to its fast growth; therefore we used direct transfer from seawater to other salinities. This study shows that $L$. vannamei have a type 3 pattern of osmoregulation, with an increasing tolerance to salinity change, from PL1 to Adult. 


\section{Materials and Methods}

\section{2. Experiments}

In an attempt to investigate the eurihalinity and osmoregulation pattern of white shrimp Litopenaeus vannamei, the effect of six salinities was evaluated on the survival of several developmental stages (Table 1) during 48h, and then on the haemolymph Osmotic Pressure (hOP) of selected developmental stages [Mysis2, PL1, PL2, PL4, PL15, Juvenile $(1.7 \pm 0.5 \mathrm{~g})$, and Adult ( $31 \pm 4 \mathrm{~g}$, both sexes)] at 12 and 24h. Both experiments were performed at AQUAPACIFIC shrimp hatchery located at El Rosario, Mazatlan, Mexico. The company provides all seawater, which is obtained with a submerged pipes system localized to $40 \mathrm{ft}$ below mean sea level in front of the hatchery shore (Pacific Ocean, el Rosario coast). The water is filtered with micro filters $(1 \mu \mathrm{m})$, ozonized, oxygenated and UV treated before use. The experimental salinities were $5,10,20,32,45$ and 60 psu. The 32 psu was the seawater used by the company during the study period; its salinity ranged from 32 to $34 \mathrm{psu}$, and in this study was considered as the control salinity. Higher salinities were obtained by adding sea salt (from Guerrero Negro, Mexico) to the seawater, and lower salinity by diluting seawater with locally purified drink water. The experimental salinities were continuously prepared and stored (two days as maximum) in 60-L containers. Salinity was adjusted in mOsm. $\mathrm{kg}^{-1}$ with a freezing point osmometer (Advanced Instruments 3320, Massachusetts). All the experiments were carried out under the same conditions: constant aeration, photoperiod $12 \mathrm{~h}$ light: $12 \mathrm{~h}$ dark and water temperature of $25 \pm 1{ }^{\circ} \mathrm{C}$ adjusted with titanium electric heaters (200 W). The shrimps were unfed during the experiments. The size of experimental unit for survival experiment was in accordance with the developmental stage (Table 1), there were three replicates for larval and PL stages, and two replicates for Juvenile and Adult (only Mysis1 stages were evaluated twice). For 
the osmotic pressure experiment, there were two replicates with about 40 larvae and PL distributed in containers of $1-\mathrm{L}$, and 15 juveniles and 12 adults in container of 20 and 60-L, respectively.

\subsection{Animal handling}

The shrimp L. vannamei were supplied by the shrimp hatchery. The larval stages were selected according to their morphology under optical microscope (Table 1). The larvae (seventh generation) came from a broodstock genetic selection program for several parameters; growth, fecundity, larval quality, genetic variability, survival and resistance to pathogens (AQUAPACIFIC, shrimp hatchery). L. vannamei has a fast growth, with 12 larval stages between nauplius to mysis (Kitani, 1986) and several PLs before reaching the adult phase (Garza-Torres et al., 2009). Under hatchery culture conditions (Mexican Pacific coast), the complete larval development of $L$. vannamei is accomplished in nine days at salinities ranging from 30 to 34 psu. The metamorphosis of the last Mysis stage marks the beginning of the PL (Post-Larval) phase (one PL stage by day), the juvenile stage is considered when body weight is over $1 \mathrm{~g}$ and the adult stage when animals have a reproductive age (Table 1) (Enrique Wong, AQUAPACIFIC hatchery manager, pers. comm.). In order to ascertain used stages, the animals were directly transferred to the experimental salinities and their stages were checked again just prior to collecting the results.

\subsection{Effect of salinity on survival}

Survival was established by the presence of movement in all animals plus the heartbeat verified under a stereoscopic microscope for all larval and postlarval stages. The number of survivors was measured at 5, 12, 24 and 48 hours post osmotic shock (hps) in each eu. Survival 
was expressed as percentage $(\mathrm{S} \%=$ [final number of live shrimp/initial number of shrimp] $\mathrm{x} 100)$ for each developmental stage. In order to determine stages with possible increasing capacity, the tolerance limits were established when S\% was equal or higher than $20 \%$ at $5 \mathrm{hps}$.

\subsection{Effect of salinity on the haemolymph Osmotic Pressure}

Just before measuring the hOP in L and PL stages, the organisms were rinsed in distilled water, carefully dried with filter paper, and quickly placed into immersion oil to avoid evaporation and to decrease movements of the animals as described by Charmantier (1998).

Juveniles and adults only were dried with filter paper. In this study, haemolymph samples ( 20 nL) were directly extract from the heart in larvae and PL using a $20 \mu \mathrm{L}$ modified glass capillary and in juvenile with a $1 \mathrm{~mL}$ insulin syringe (gauge 31 ); in adult, haemolymph was sampled from the ventral sinus with $1 \mathrm{~mL}$ insulin syringe. Both hOP and water osmotic pressure (wOP) were measured before any salinity shock (Table 2) and then at 12 and 24 hps. Osmotic Pressures in larvae and PL were measured with a nano osmometer (Otago Osmometer, New Zealand) and in juvenile and adult with a micro osmometer (Advanced Instruments Osmometer 3320, Massachusetts), at least six animals. Collecting haemolymph sample from nauplius and zoea was not successful due to their small size. The Fusion Temperature value (FT) obtained with the nano osmometer is transformed to mOsm. $\mathrm{kg}^{-1}$ using Osmotic Pressure $=(1000 \mathrm{x}$ FT $) / 1.858$.

Both osmotic pressures (hOP and wOP) were correlated to calculate a linear regression model for each developmental stage in order to evaluate the slopes of the regression curve as indicative of the osmoregulatory capabilities as in Ferraris et al. (1986); a value of 1 indicates osmoconformation. The Osmoregulatory Capacity (OC) is determined by the difference between the hOP and the wOP in each salinity (Lignot et al., 2000), and it was calculated for each 
developmental stage. The hyper-osmoregulatory pattern occurs when the $\mathrm{OC}$ value is positive in low salinities and hypo-osmoregulatory pattern when it is negative in high salinities. The Isosmotic Point (IP) was calculated for each developmental stage using the intersection of the calculated regression line with the iso-osmoconformation line.

\subsection{Statistical analysis}

The survival percentage (S\%) and OP were normalized with arcsine and square root, respectively. We used a Slope Test to compare the osmoregulatory abilities among developmental stages (Ferraris et al., 1986). One-way ANOVA with a Tukey post hoc test was used to evaluate the statistical significance of differences between stages. Values of $p<0.05$ were considered significant. Comparisons were performed using GraphPad Prism package version 5.0a for Mac OS X (San Diego, California USA). All graphs correspond to untransformed data (mean \pm SEM). Salinity was expressed in practical salinity units (psu) and osmotic pressures in milliosmoles $/ \mathrm{kg}\left(\mathrm{mOsm} \cdot \mathrm{kg}^{-1}\right)$.

\section{Results}

\subsection{Euryhalinity}

As outlined in the introduction, the shrimps have different osmoregulatory abilities during ontogeny. It is apparent that salinity tolerance of Litopenaeus vannamei progressively increased with age (Fig. 1). The larval stages (Nauplius, Zoea, Mysis) and PL1 only tolerates salinities of 20, 32 and 45 psu. But, this tolerance increases in PL2 and PL4, when they survive also in 10 and 5 psu, respectively. The maximum euryhalinity occurred in PL22, PL27, Juveniles, and Adults, with more than 20 percent survival (\%S) in all experimental salinities 
(including the maximum salinity evaluated; 60 psu). Mysis1 survives in 10 psu (>20\%), while the preceding stages Mysis2, Mysis3, and PL1 had zero survival in that salinity (Fig. 1). Since there is no survival at $10 \mathrm{psu}$ in Nauplius, Zoea, Mysis2, Mysis3 and PL1, the survival of Mysis1 at this salinity becomes significant and unexpected $(\mathrm{p}<0.05)$.

Nevertheless, the capability of L. vannamei for survival (with $\% \mathrm{~S} \geq 20 \%$ ) in each experimental salinity varied during the experiment (48 hps; Fig. 2). At 12 hps the \%S was lower than $20 \%$ for M1 in 10 psu, and also in PL22 and PL27 in 60 psu (Fig. 2B and F). At 24 hps, the Adult stage has a dramatic mortality in 5 psu $(\% \mathrm{~S}=5)$, while all Mysis1 died in 10 psu (Fig. 2A and B). At the end of the experiment, the $\% \mathrm{~S}$ was lower in 20 psu for Mysis2 (Fig. 2C), for PL1 and PL3 in 45 psu (Fig. 2E) and for Adult stage in 60 psu (Fig. 2F). As can be seen in Figure 2F, only in Juvenile stage the survival was highest during $48 \mathrm{~h}$. The shrimp behavior in 45 psu was characterized by increased hyperactivity and cannibalism in initial PL stages (PL1-PL7), while Mysis2 and Adult showed a protuberance on the cephalothorax in 20 and 5 psu, respectively (Fig. 3A and B).

\section{2. Ontogeny of osmoregulatory pattern}

To delimit the ontogeny of osmoregulatory pattern of $L$. vananmei we quantify the hOP at 12 and $24 \mathrm{hps}$ in selected developed stages. The hOPs are not significantly different $(\mathrm{p}<0.05)$, therefore only results from 24 hps are given in figure 4 . The hOP values showed a type 3 pattern of osmoregulation for L. vananmei. The slope calculated decreased from Mysis2 to Adult, but no significantly differences were detected between PL's slopes (from PL1 to PL15), while Juvenile and Adult slopes were significantly different from either PL's or Mysis2 slopes (Fig. 4, p> 0.05). 
The OC of Mysis2 in 20 psu was low and positive, but slightly higher and negative (27 mOsm.kg ${ }^{-1}$ ) in 32 and 45 psu (Fig. 5). These results, and the slope calculated close to one (>0.8) suggest a type of iso-osmoregulation pattern with weakly hyper-osmoregulation pattern in salinities of 32 and 45 for mysis stage. Osmoregulation pattern in PL1, and so on, was similar to that observed in Juvenile and Adult (Fig. 4).

The OC of each developmental stage was higher as animals were exposed to salinities farther from the IP (Fig. 5). The highest OC was detected in Juvenile and Adult in extreme salinity (5, and $60 \mathrm{psu}$ ). But, there were significantly differences between these stages in salinity of 5 psu (Fig. $5 ; \mathrm{p}>0.05$ ). The OC in the other experimental salinities was significantly different between almost all developmental stages (Fig. 5; p>0.05). These results demonstrate that the OC vary with salinity, per se, but mostly among developmental stages and other possible animal condition as suggest by Lignot (2000). Comparing figures 1 and 5 became clear that OC value becomes higher with more salinity stress; the PL1 surviving in 10 psu has higher OC than OC in 20 and $32 \mathrm{psu}$, suggesting that the hydromineral balance is affected in that salinity, and correspondingly there was an effect on survival (Fig. 1). Future work will involve better understanding of the osmoregulation function, from cellular morphology to gene expression.

\section{Discussion}

L. vannamei displays a type 3 pattern of osmoregulation during ontogeny, in which metamorphosis marks the appearance of the adult type of osmoregulation (Charmantier, 1998). Following last metamorphosis, salinity tolerance progressively increased in PL2, PL4, and PL22, with Juvenile as the strongest osmoregulator (they were able to survival in all our tested salinities; 5, 10, 20, 32, 45, and $60 \mathrm{psu}$, during 48h trail). Tolerance to low salinity (5 psu) was 
observed from PL4, while tolerance to 60 psu (high salinity) occurred in PL39. Suggesting that there are key changes in the development of the corresponding osmoregulatory capabilities, as occur in other penaeid shrimps (Bouaricha et al., 1994; Pham et al., 2012a).

The osmoregulatory patterns are adaptive strategies acquired during evolution (Charmantier, 1998). The change in the pattern from larvae stages to PL possibly is in agreement with the general developmental process of L. vannamei. In species with a biphasic life cycle, radical ontogenetic transitions of habitat and life style occur, implying dramatic changes in vital functions; the larvae present stage-specific adaptations to the pelagic environment where the larvae live and develop, floating in the water column and they significantly differ from their conspecific juvenile and adult (Anger, 2006). For example, in lobster of genus Homarus the change in osmoregulation pattern would be part of the physiological changes, associated to morphological, anatomical and ecoethological changes that happen at that time and are linked to a change in habitat (Charmantier et al., 1991).

The ontogeny of osmoregulation pattern of L. vannamei is similar to those known for other decapod shrimps that have a biphasic life cycle such as P. japonicus, L. stylirrostris and Crangon crangon. In these species, euryhalinity and osmoregulatory capabilities are related to the development of specialized osmoregulatory structures such as the pleura, branchiostegite, epipodite and gills (Charmantier et al., 1988; Cieluch et al., 2004; Pham et al., 2012a). To date, there is no available information on L. vannamei osmoregulatory capabilities at the cellular and molecular level, but it is possible that similar mechanisms would be involved in those responses (Chong-Robles et al, in prep).

The limited tolerance to salinity changes observed for larvae is in agreement with the fact that they live and develop under stable salinity conditions, in the ocean (FAO, 2004). However, our 
results showed that Mysis stages have little ability to survive at low salinity ( $20 \mathrm{psu}$ ) while Nauplius and Zoea stages survive well. This result suggests that Mysis stages most probably require certain salinity level for an optimal development. During this stage, dramatic morphological changes occur, which mark the transition between herbivore to carnivore feeding behavior (Abrunhosa and Melo, 2008). It will be necessary to study larval development under different salinities to corroborate this hypothesis, as good tolerance is not equivalent to good development.

The PL stages showed a progressive increase in salinity tolerance according to their life cycle. The recruitment to coastal zones occurs when the animals have the ability to functionally adapt to the dynamic environment (McKenney and Celestial, 1995). The recruitment of $L$. vannamei is reported for PL that measures between 4.8 - $6.1 \mathrm{~mm}$ of total length (Ramos-Crúz and Ramos-Santiago, 2006). Our results provide insight that the colonization might occur from PL2 to PL4, however it is necessary to corroborate their actual size in their natural habitat where the conditions growth varies.

The euryhalinity of $L$. vannamei during ontogeny is slightly higher than that of $L$. stylirostris and P. japonicus. In our study, PL4 survives more than $50 \%$ at 5 and 10 psu, while the lethal salinity reported for L. stylirrostris PL4 is 17 psu (Pham et al., 2012b) and the lethal salinity for P. japonicus PL2 to PL6 is 10 psu (Charmantier et al., 1988).

We corroborate that in L. vannamei, the tolerance to low salinity increases progressively from PL2, but we noted differences for the key stages reported by Aquacop et al. (1991) in the same species. In our experiments, PL4 is able to tolerate salinity of 5 psu, and PL2 and PL3 can tolerate 10 psu, while in Aquacop's (1991) study, PL2 and PL3 only tolerated a salinity of 20 psu and the tolerance to low salinity occurred from PL20. Our results are in agreement with the high 
survival detected by Jayasankar et al. (2009), still in the same species, for PL15 and Juvenile in 5 psu and with the high survival for PL22 at 22, 25, and 28 psu reported previously by Pan et al. (2007).

During the experiments, survival decreased for almost all stages (an exception was Juvenile stage) and salinities (even at the control salinity, $32 \mathrm{psu}$ ). For instance, in larvae and PL stages this trend may be related to the absence of food, as osmoregulation requires energy. The effect of starvation under osmotic stress has been demonstrated in PL20: the magnitude of survival is low in unfed organisms (Palacios et al., 2004). Also, during these stages occur the development of other major systems such as the digestive system (Abrunhosa and Melo, 2008) and the reproductive organs (Garza-Torres et al., 2009), in parallel with the development of osmoregulatory organs that implies an energy expenditure.

The low survival rates observed in Adult at $5 \mathrm{psu}(24 \mathrm{hps})$ and, $60 \mathrm{psu}(48 \mathrm{hps})$ may have been related to salinity stress that affect animal physiology as occur in L. stylirostris (Lignot et al., 1999). In this study, adults were animals taken from the breeding season. Even though, in other penaeid shrimps (P. monodon, P. merguiensis, P. plebejus, P. esculentus, and Metapenaeus bennettae) it has been suggested that the Adult stage lose the osmoregulatory ability because they live in stenohaline environments, as ocean (Cawthorne et al., 1983; Dall, 1981). Our results warrant further investigations in stages between Juvenile $(1.8 \pm 0.2 \mathrm{~g})$ and Adult $(46 \pm 2 \mathrm{~g})$ to discard the possible effect of reproduction on the osmoregulation results or to find any difference associated to animal conditions.

The hOP was stable since $12 \mathrm{hps}$ in all studied developmental stages; from M2 to Adult. In P. japonicus the stabilization of hOP varies according to developmental stage: only 6 hps in PL10 and 12 hps in Juvenile are necessary for the establishment of a stable hOP (Charmantier et 
al., 1988). In L. vannamei, hOP stabilization was probably established as $P$. japonicus, but our experiment was not designed to test it. The iso-osmotic points (IPs) observed for $L$. vannmaei are similar to those previously reported for Juvenile and Adult (Bückle et al., 2006; Castille and Lawrence, 1981) suggesting that the IP does not vary during ontogeny.

\section{Conclusion}

L. vannamei is able to hyper-hypo osmoregulate since PL1 stage but later important increases in salinity tolerance suggest that the specialized epithelium for osmoregulation is gradually acquired. It is necessary study how the development of gill and other osmoregulatory structures are correlated at the cellular and molecular levels with the increase of OC and higher tolerance to salinity variations during development, observed in PL2, PL4 and PL22. In culture production systems, a common practice is to match environmental salinity to the IP of the species. However, as demonstrated for the shrimp Macrobrachium rosenbergii (Singh, 1980) and in L. vannamei (see Feng et al., 2008), both survival and growth occur in conditions "close to IP". Apparently, the IP is not a good indicator of the ideal condition to optimize growth. A better growth results by using salinity fluctuation (Feng et al., 2008) more than a stable IP salinity as suggested by Valdez et al. (2008). In other invertebrates, as the sand dollar sea urchin Dendraster excentricus, a better development and bigger juveniles are obtained when the salinity is variable (George and Walker, 2007). In L. vannamei, the hyper-hypo osmoregulatory pattern in PL and Juvenile could be used for exploring the physiological plasticity during ontogeny of this species under culture conditions, to improve growth conditions and better acclimatizing procedures in animals before they reach the end of their growth. 


\section{Acknowledgements}

This project was funded by CONACyT-Ciencia básica I0110/194/09 allocated to IGM and a

PhD grant 184694 to JCR. We thank the staff from AQUAPACIFIC, in particular Enríque Wong and Leonardo Sainz. 


\section{References}

Abrunhosa, F., Melo, M., 2008. Development and functional morphology of the foreguts of larvae and postlarvae of three crustacean decapods. Brazilian Journal of Biology. $68,221-228$.

Anger, K., 2006. Contributions of larval biology to crustacean research: a review. Invertebrate Reproduction and Development. 49, 175-205.

Aquacop, R., Le Moullac, G., Damez, D., 1991. Modélisation de la résistance aux chocs de salinité des postlarves de Penaeus vannamei. Aquatic Living Resources. 4, 169173.

Balbi, F., Rosas, J., Velásquez, A., Cabrera, T., Maneiro, C., 2005. Aclimatación a baja salinidad de postlarvas del camarón marino Litopenaeus vannamei (Boone, 1931) provenientes de dos criaderos comerciales. Revista de Biología Marina y Oceanografía. 40, 109 - 115.

Bouaricha, N., M. Charmantier-Daures, P. Thuet, J-P. Trilles, Charmantier, G., 1994. Ontogeny of Osmoregulatory Stuctures in the Shrimp Penaeus japonicus (Crustacea, Decapoda). Biological Bulletin. 186, 29-40.

Bückle, L.F., Barón, B., Hernández, M., 2006. Osmoregulatory capacity of the shrimp Litopenaeus vannamei at different temperatures and salinities, and optimal culture environment. Revista de Biología Tropical. 54, 745-753.

Castille, F.L., Jr., Lawrence, A.L., 1981. The effect of salinity on the osmotic, sodium and chloride concentrations in the hemolymph of euryhaline shrimp of the genus Penaeus. Comparative Biochemistry and Physiology, Part A: Molecular \& Integrative Physiology. 68, 75-80.

Cawthorne, D.F., Beard, T., Davenport, J., Wickins, J.F., 1983. Responses of juvenile Penaeus monodon Fabricius to natural and artificial sea waters of low salinity. Aquaculture. 32, 165-174.

Charmantier, G., 1998. Ontogeny of osmoregulation in crustaceans: a review. Invertebrate Reproduction and Development. 33, 177-190.

Charmantier, G., Wolcott, D.L., 2001. Introduction to the Symposium: Ontogenetic Strategies of Invertebrates in Aquatic Environments. American Zoology. 41, 1053-1056.

Charmantier, G., Charmantier-Daures, M., Aiken, D.E., 1991. Metamorphosis in the lobster Homarus (Decapoda): a review. Journal of Crustacean Biology. 11, 481-495.

Charmantier, G., M., C.-D., D., T., 2009. Osmotic and ionic regulation in aquatic arthropods. in: Evans, D.H. (Ed.), Osmotic and ionic regulation. Cells and animals. CRC Press, Boca Raton, FL, New York, UK, pp. 165-230. 
Charmantier, G., M. Charmantier-Daures, N. Bouricha, P. Thuet, D. E. Aiken, Trilles, J.-P., 1988. Ontogeny of Osmoregulation and Salinity Tolerance in Two Decapod Crustaceans: Homarus americanus and Penaeus japonicus. The Biological Bulletin. 175, 102-110.

Cieluch, U., Klaus, A., Aujoulat, F., Buchholz, F., Charmantier-Daures, M., Charmantier, G., 2004. Ontogeny of osmoregulatory structures and functions in the green crab Carcinus maenas (Crustacea, Decapoda). Journal of Experimental Biology. 207, 325-336.

Dall, W., 1981. Osmoregulatory ability and juvenile habitat preference in some penaeid prawns. Journal of Experimental Marine Biology and Ecology. 54, 55-64.

Díaz, F., Farfan, C., Sierra, E., Re, A.D., 2001. Effects of temperature and salinity fluctuation on the ammonium excretion and osmoregulation of juveniles of Penaeus vannamei, Boone. Marine and Freshwater Behaviour and Physiology. 34, 93-104.

Esparza-Leal, H.M., Ponce-Palafox, J.T., Aragón-Noriega, E.A., Arredondo-Figueroa, J.L., Gómez, M.G.-U., Valenzuela-Quiñonez, W., 2010. Growth and performance of the whiteleg shrimp Penaeus vannamei (Boone) cultured in low-salinity water with different stocking densities and acclimation times. Aquaculture Research. 41, 878-883.

FAO, 2004. Manejo sanitario y mantenimiento de la bioseguridad de los laboratorios de postlarvas de camarón blanco (Penaeus vannamei) en América Latina, FAO Documento Técnico de Pesca, pp. 66.

FAO, 2011. El estado mundial de la pesca y la acuicultura (SOFIA), Topic Fact Sheets. Departamento de Pesca y Acuicultura de la FAO (en línea), Roma.

Feng, C., Tian, X., Dong, S., Su, Y., Wang, F., Ma, S., 2008. Effects of frequency and amplitude of salinity fluctuation on the growth and energy budget of juvenile Litopenaeus vannamei (Boone). Aquaculture Research. 39, 1639-1646.

Ferraris, R.P., Parado-Estepa, F.D., Ladja, J.M., de Jesus, E.G., 1986. Effect of salinity on the osmotic, chloride, total protein and calcium concentrations in the hemolymph of the prawn Penaeus monodon (FABRICIUS). Comparative Biochemistry and Physiology, Part A: Molecular \& Integrative Physiology. 83A, 701-708.

Garza-Torres, R., Campos-Ramos, R., Maeda-Martínez, A.M., 2009. Organogenesis and subsequent development of the genital organis in female and male Pacific white shrimp Penaeus (Litopenaeus) vannamei. Aquaculture. 296, 136-142.

George, S.B., Walker, D., 2007. Short-term fluctuation in salinity promotes rapid larval development and metamorphosis in Dendraster excentricus. Journal of Experimental Marine Biology and Ecology. 349, 113-130. 
Jayasankar, V., Jasmani, S., Nomura, T., Nohara, S., Huong, D.T.T., Wilder, M.N., 2009. Low Salinity Rearing of the Pacific White Shrimp Litopenaeus vannamei: Acclimation, Survival and Growth of Postlarvae and Juveniles. JARQ. 43, 345-350.

Kitani, H., 1986. Larval Development of the White Shrimp Penaeus vannamei BOONE Reared in the Laboratory and the Statistical Observation of its Naupliar Stages. Bulletin of the Japanese Society of Scientific Fisheries. 52, 1131-1139.

Laramore, S., Laramore, C.R., Scarpa, J., 2001. Effect of Low Salinity on Growth and Survival of Postlarvae and Juvenile Litopenaeus vannamei. Journal of the World Aquaculture Society. 32, 385-392.

Lignot, J.-H., C. Spanings-Pierrot, Charmantier, G., 2000. Osmoregulatory capacity as a tool in monitoring the physiological condition and the effect of stress in crustaceans. Aquaculture. 191 209-245.

Lignot, J.H., Cochard, J.C., Soyez, C., Lemaire, P., Charmantier, G., 1999. Osmoregulatory capacity according to nutritional status, molt stage and body weight in Penaeus stylirostris. Aquaculture. 170, 79-92.

McGraw, W.J., Davis, D.A., Teichert-Coddington, D., Rouse, D.B., 2002. Acclimation of Litopenaeus vannamei Postlarvae to Low Salinity: Influence of Age, Salinity Endpoint, and Rate of Salinity Reduction. Journal of the World Aquaculture Society. 33, 78-84.

McKenney, C., Jr., Celestial, D.M., 1995. Interactions among salinity, temperature and age on growth of the estuarine mysid Mysidopsis bahia reared in the laboratory through a complete life cycle. Journal of Crustacean Biology. 15, 169-178.

Palacios, E., Bonilla, A., Luna, D., Racotta, I.S., 2004. Survival, Na+/K+-ATPase and lipid responses to salinity challenge in fed and starved white pacific shrimp (Litopenaeus vannamei) postlarvae. Aquaculture. 234, 497- 511.

Pan, L.-Q., Zhang, L.-J., Liu, H.-y., 2007. Effects of salinity and pH on ion-transport enzyme activities, survival and growth of Litopenaeus vannamei postlarvae. Aquaculture. 273 711-720.

Péqueux, A., Dandrifosse, G., Loret, S., Charmantier, G., Charmantier-Daures, M., SpaningsPierrot, C., Schoffeniels, E., 2006. Osmoregulation: Morphological, physiological, bio-chemical, hormonal, and developmental aspects. in: Forest, J., Klein, J.C.v.V. (Eds.), The Crustacea. Brill, Leiden, Boston, pp. 205.

Pham, D., Charmantier, G., Boulo, V., Wabete, N., Grousset, E., Charmantier-Daures, M., 2012a. Osmoregulation in the penaeid shrimp Litopenaeus stylirostris : ontogeny and localization of transporters, SICB Annual Meeting, Charleston, SC, USA.

Pham, D., Charmantier, G., Wabete, N., Boulo, V., Broutoi, F., Mailliez, J.-R., Peignon, J.-M., Charmantier-Daures., M., 2012b. Salinity tolerance, ontogeny of osmoregulation 
and zootechnical improvement in the larval rearing of the Caledonian Blue Shrimp, Litopenaeus stylirostris (Decapoda, Penaeidae). Aquaculture. 362-363, 10-17.

Ponce-Palafox, J., Martinez-Palacios, C.A., Ross, L.G., 1997. The effects of salinity and temperature on the growth and survival rates of juvenile white shrimp, Penaeus vannamei, Boone, 1931. Aquaculture. 157, 107-115.

Rámos-Carreño, S., Giffard-Mena, I., Valencia-Yañez, R., Correa-Sandoval, F., Ruíz-García, N., Díaz-Herrera, F., 2013. White Spot Syndrome Virus (WSSV) infection in Penaeus vannamei exposed to extreme salinities. Archives of Virology. in press.

Ramos-Crúz, S., Ramos-Santiago, E., 2006. Abundancia relativa de postlarvas de camarones penéidos en la Bahía Salinas del Marqués, Golfo de Tehuantepec, México. Marzo a Junio de 1999. Revista de Biología Marina y Oceanografía. 41, 121-128.

Singh, T., 1980. The isosmotic concept in relation to the aquaculture of the giant prawn, Macrobrachium rosenbergii. Aquaculture. 20, 251-256.

Sowers, A.D., Young, S.P., Grosell, M., Browdy, C.L., Tomasso, J.R., 2006. Hemolymph osmolality and cation concentrations in Litopenaeus vannamei during exposure to artificial sea salt or a mixed-ion solution: Relationship to potassium flux. Comparative Biochemistry and Physiology, Part A: Molecular \& Integrative Physiology. 145, 176-180.

Valdéz, G., Fernando Díaz, Re, A.D., Sierra, E., 2008. Efecto de la salinidad sobre la fisiología energética del camarón blanco Litopenaeus vannamei (Boone). Hidrobiológica. $18,105-115$.

Young, B.A., B. Walker, Dixon, A.E., Walker, V.A., 1989. Physiological Adaptation to the Environment. Journal of Animal Science. 67, 2426-2432.

Zhang, P., Zhang, X., Li, J., Gao, T., 2009. Effect of salinity on survival, growth, oxygen consumption and ammonia-N excretion of juvenile whiteleg shrimp, Litopenaeus vannamei. Aquaculture Research. 40, 1419-1427. 


\section{Figure legends}

Figure 1. L. vannamei survival during ontogeny at 5 hps. N2, nauplius 2; N6, nauplius 6; Z3, zoea 3; M1, 2 and 3 are respectively mysis 1, 2 and 3; PL1, 2, 3, 4, 5, 7, 12, 15, 19, 22 and 27 correspond to postlarval stages, the number indicates the day after metamorphosis. Stages are considered tolerant for survival equal or higher than $20 \%$. Bars sharing different letter are significantly different $(\mathrm{P}<0.05)$.

Figure 2. L. vannamei survival (\%) in six salinities according to time up to $48 \mathrm{hps}$. A, $5 \mathrm{psu}$; B, $10 \mathrm{psu} ; \mathrm{C}, 20 \mathrm{psu}$; D, $32 \mathrm{psu}$; E, 45 psu; F, 60 psu. Each line or set of lines corresponds to each developmental stage. Dashed line indicates survival of 20 and $50 \%$ at each salinity. N2, Nauplius 2; N6, Nauplius 6; Z3, Zoea 3; M1, 2 and 3 are respectively mysis 1, 2 and 3; PL1, 2, 3, 4, 5, 7, $12,15,19,22$ and 27 correspond to postlarval stages, where the number indicates the day after metamorphosis.

Figure 3. L. vannamei visible anatomical abnormalities at the end of the experiment. A, M3 exposed to $20 \mathrm{psu}$; B, Ventral view of adult carapace exposed to $5 \mathrm{psu}$; C, M3 at $32 \mathrm{psu}$; D, ventral view of adult carapace at $32 \mathrm{psu}$. The arrow indicates the protuberance of the cephalothorax in M3 and adult in 20 and 5 psu, respectively.

Figure 4. L. vannamei osmoregulation pattern at 24 hps in selected stages. M2, Mysis 2; PL1, Postlarva 1; PL2, Postlarva 2; PL4, Postlarva 4; PL15, Postlarva 15; J, Juvenile; A, Adults. The graphic shows a range of IP (Isosmotic Points) corresponding to all stages, except for M2. 
Figure 5. L. vannamei osmoregulatory capacity in each salinity, and developmental stage at 24 hps. A, Mysis 2; B, Postlarva 1; C, Postlarva 2; D, Postlarva 4; E, Postlarva 15; F, Juvenile; G, Adult. OC, Osmoregulatory Capacity. hps, hours post osmotic shock. Bars sharing different letter are significantly different $(\mathrm{P}<0.05)$. 


\section{Tables}

Table 1. L. vannamei developmental stages used during the survival experiment. Size in mm (mean \pm SEM), volume of the experimental units (eu) in liters, and number of organisms at the beginning of experiment.

Table 2. L. vannamei initial osmotic pressures for haemolymph and water (mean $\pm \mathrm{SEM})$ in mOsm.kg ${ }^{-1}$. M2, Mysis 2; PL1, Postlarva 1; PL2, Postlarva 2; PL4, Postlarva 4; PL15, Postlarva 15; J, Juvenile; A, Adult. 
5 psu
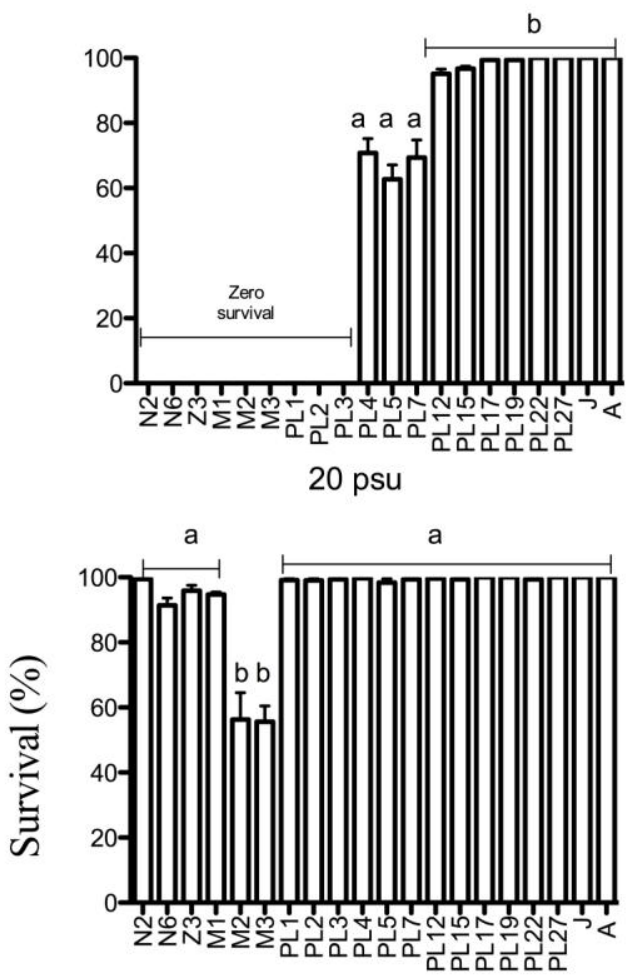

45 psu

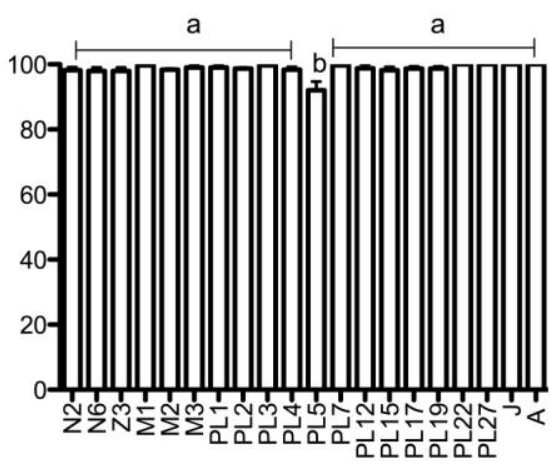

10 psu
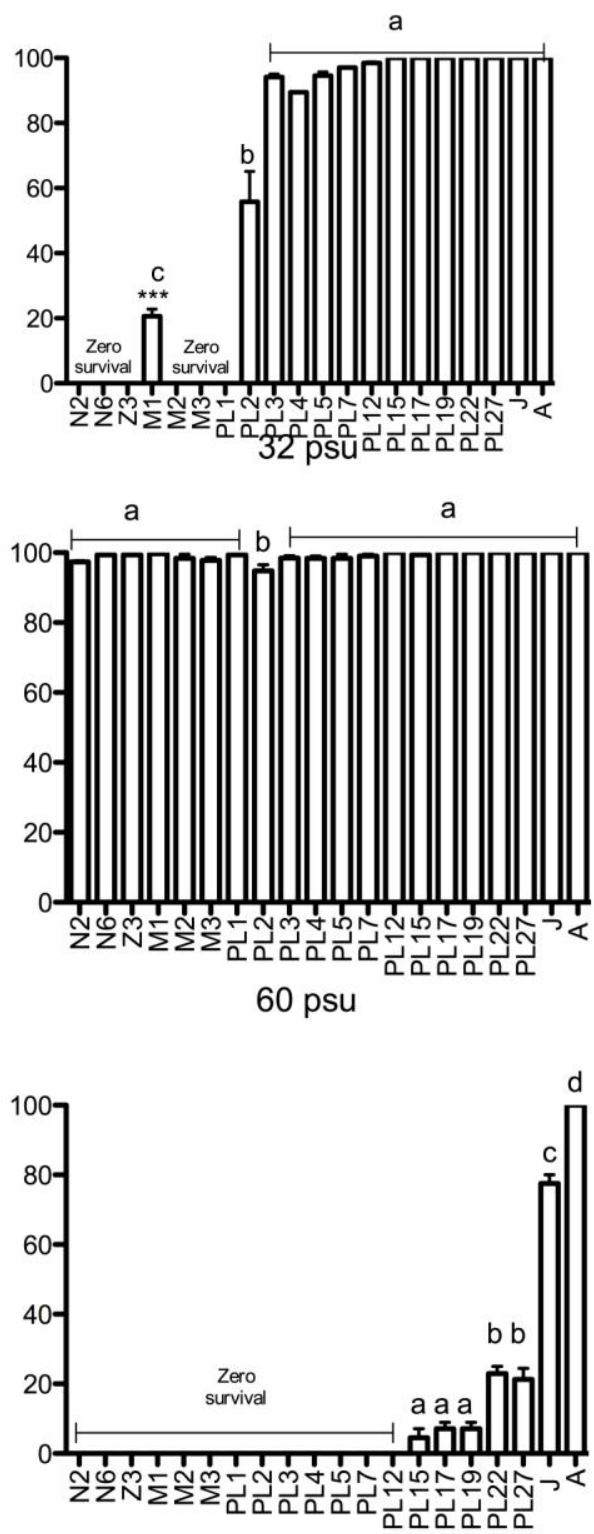

Developmental stage

Figure 1 

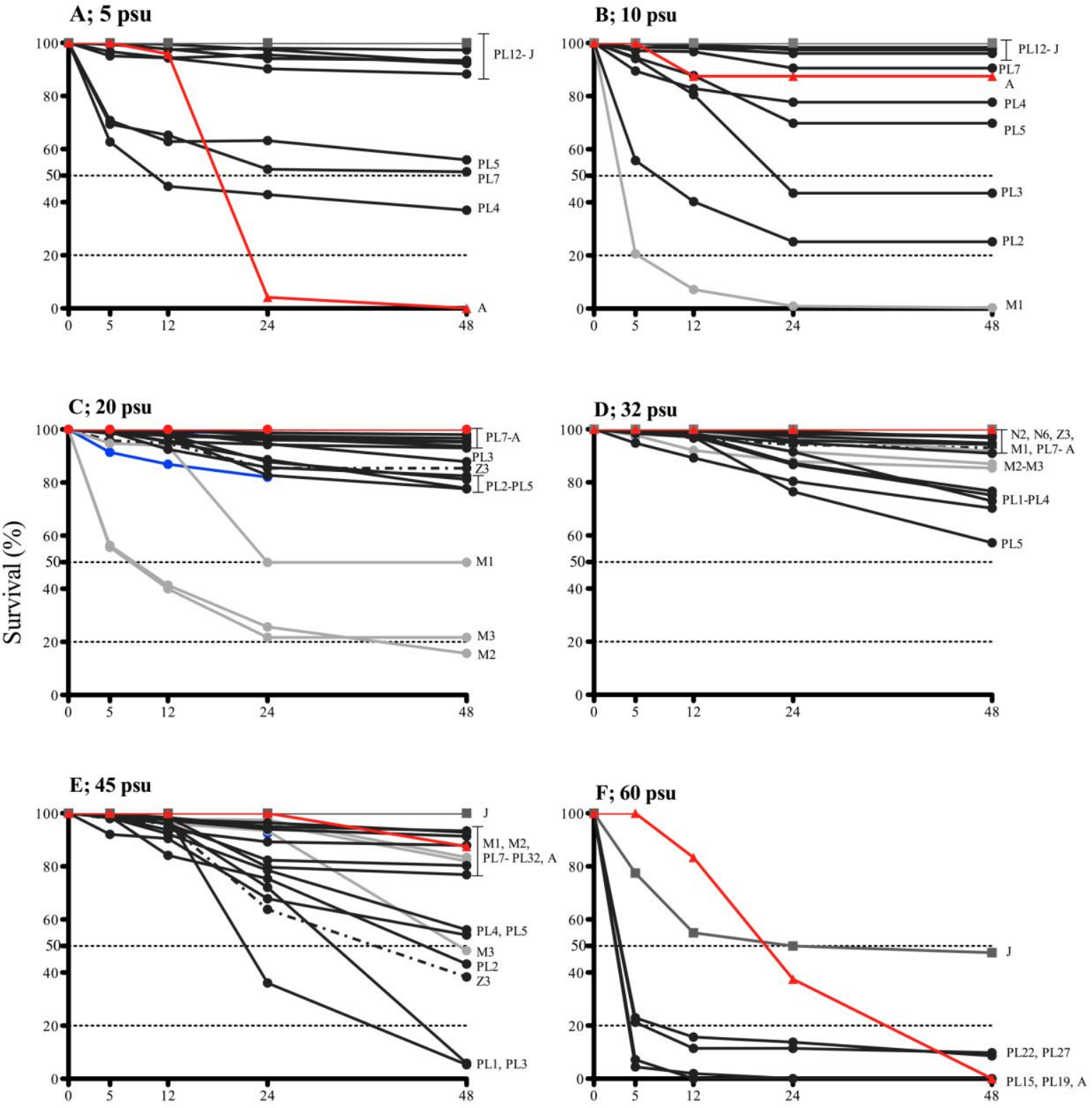

Time (hours post osmotic shock)

Figure 2 


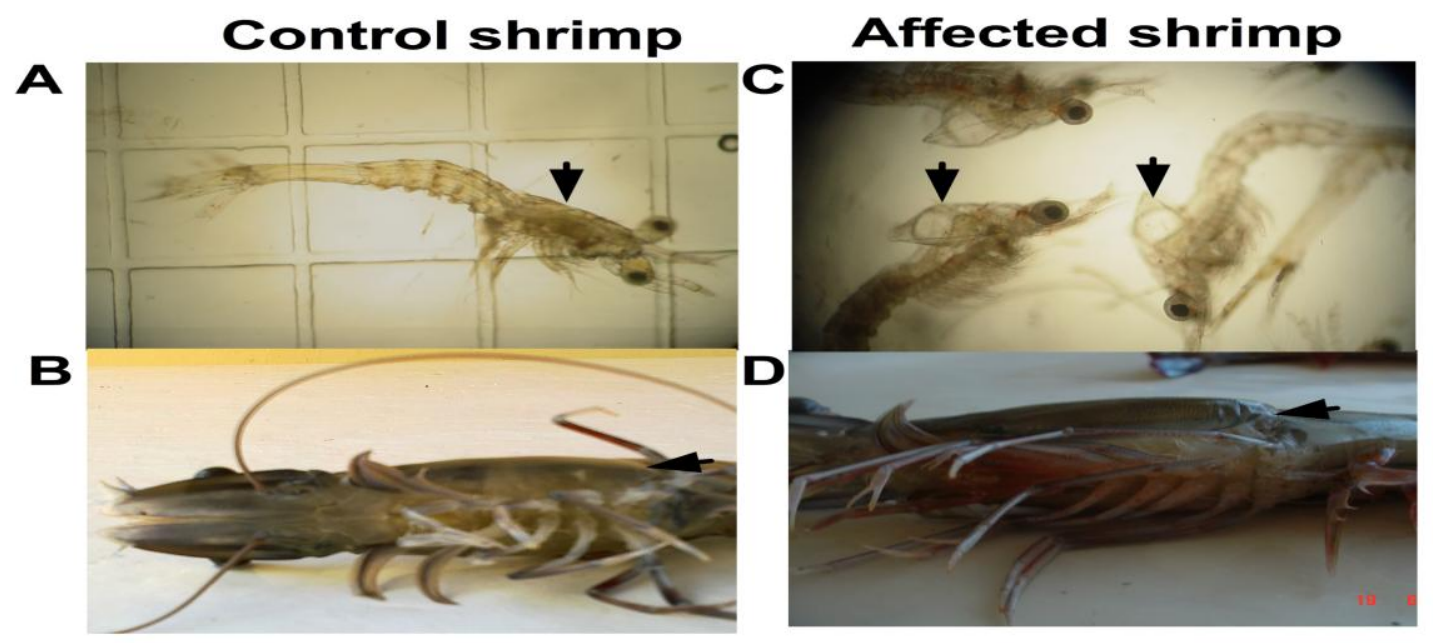

Figure 3 


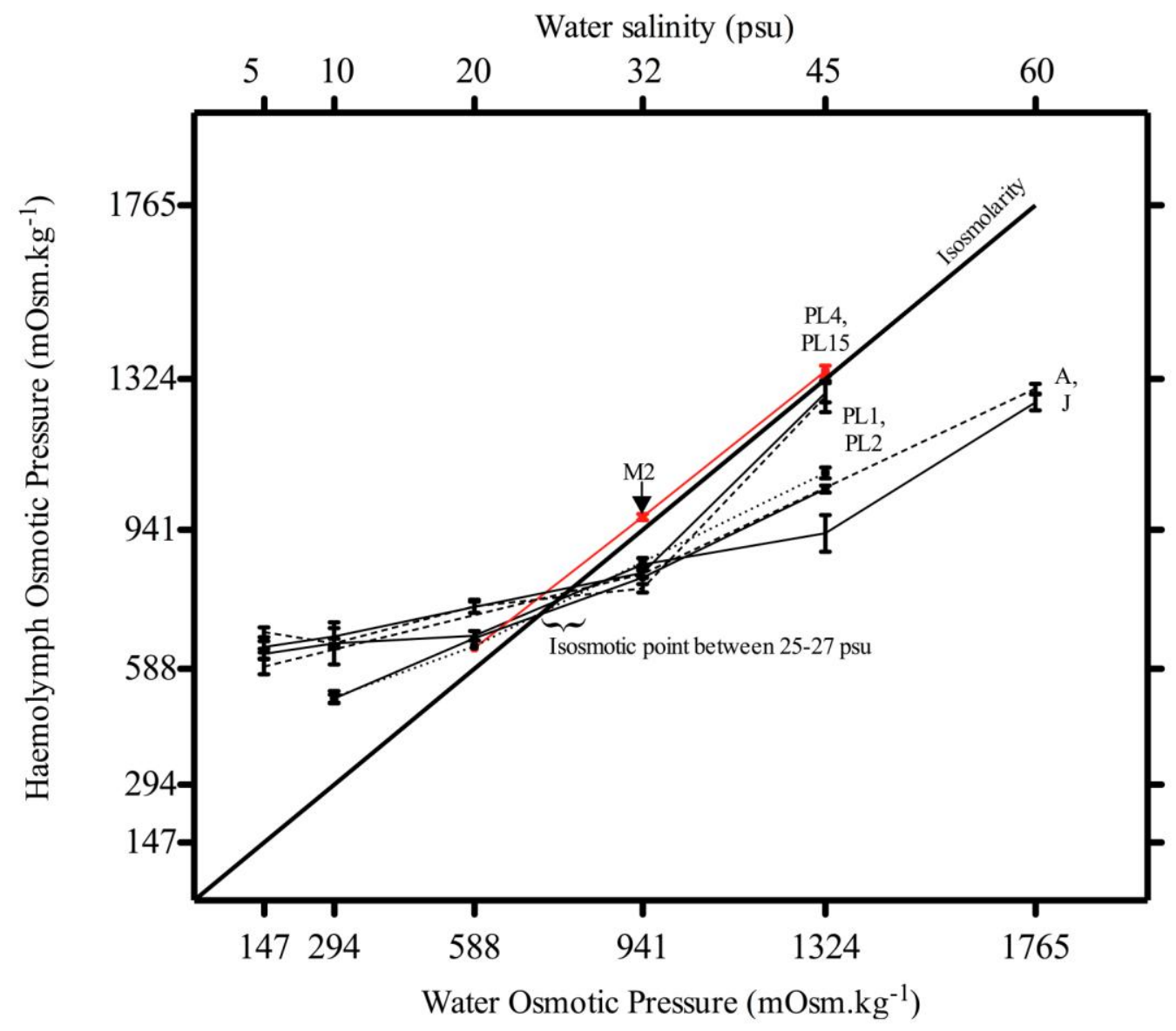

Figure 4 


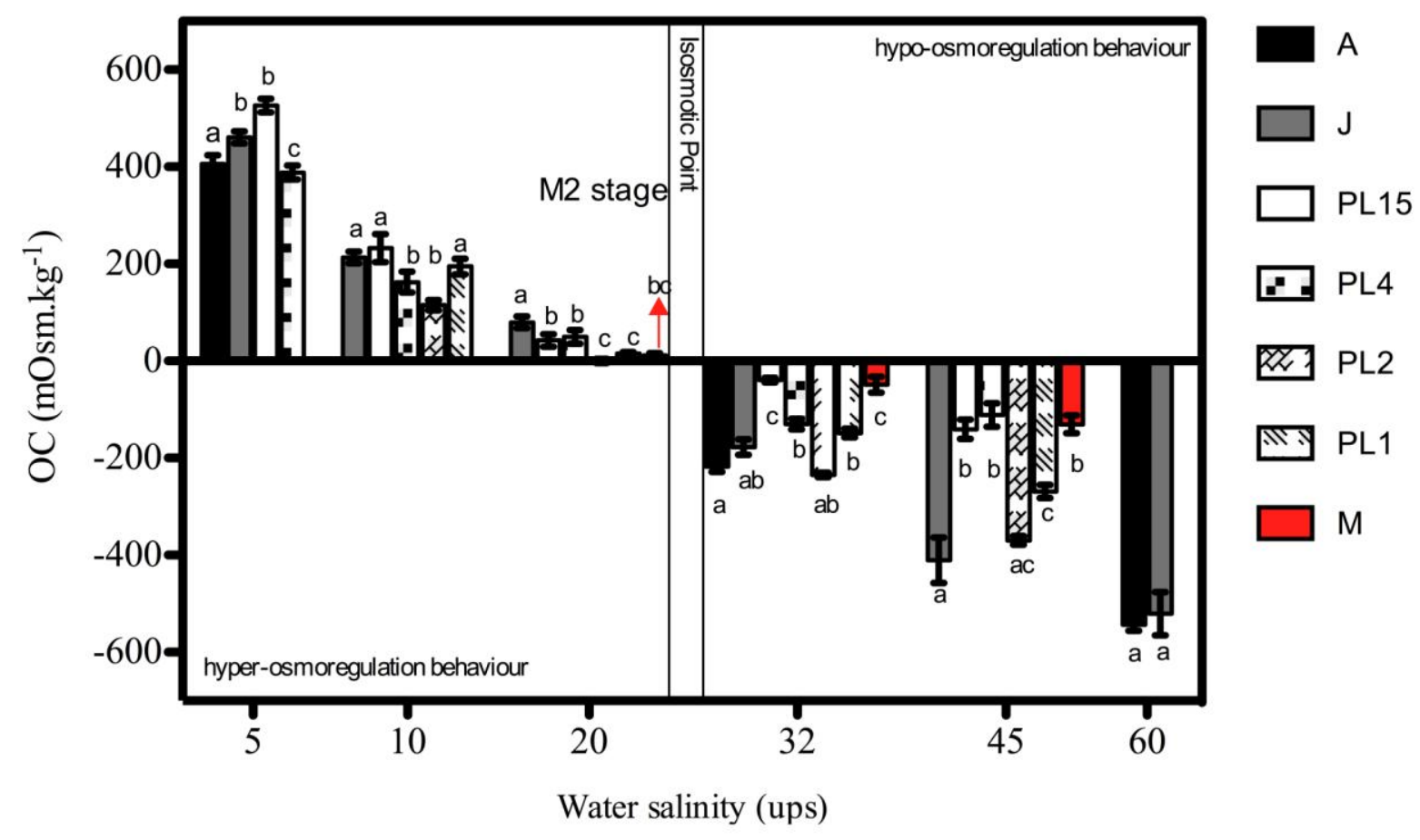

Figure 5 
Table 1.

\begin{tabular}{|c|c|c|c|c|}
\hline Developmental stages & Size in length & Abrev. & Initial $\mathrm{N}$ & $\begin{array}{l}\text { Eu capacity in L } \\
\text { (water volume). }\end{array}$ \\
\hline Nauplius 2 & $0.4 \pm 0.15$ & N2 & 110 & \\
\hline Nauplius 6 & $0.5 \pm 0.03$ & N6 & 116 & \\
\hline Zoea 3 & $1.4 \pm 0.03$ & $\mathrm{Z3}$ & 11 & \\
\hline Mysis 1 & $3.2 \pm 0.08$ & M1 & 106 & \\
\hline Mysis 2 & no data & M2 & 106 & \\
\hline Mysis 3 & no data & M & 106 & \\
\hline Postlarva 1 & $5 \pm 0.05$ & PL1 & 112 & \\
\hline Postlarva 2 & $6.2 \pm 0.08$ & PL2 & 103 & \\
\hline Postlarva 3 & $6.3 \pm 0.07$ & PL3 & 110 & \\
\hline Postlarva 4 & $6.8 \pm 0.07$ & PL4 & 104 & \\
\hline Postlarva 5 & $7.2 \pm$ & PL5 & 106 & \\
\hline Postlarva 7 & $7.4 \pm 0.10$ & PL7 & 105 & $10(5)$ \\
\hline Postlarva 12 & $2 \pm 0.17$ & PL12 & 82 & \\
\hline Postlarva 15 & data & PL15 & 53 & \\
\hline Postlarva 19 & $11.8 \pm 0.26$ & PL19 & 52 & \\
\hline Postlarva 22 & $12 \pm 0.33$ & PL22 & 51 & \\
\hline Postlarva 27 & $17 \pm 0.56$ & PL27 & 41 & \\
\hline Juvenile & $6 \pm 0.18$ & $\mathrm{~J}$ & 20 & $40(30)$ \\
\hline Adult & $21 \pm 0.35$ & A & 12 & $700(400)$ \\
\hline
\end{tabular}


Table 2.

\begin{tabular}{ccc}
\hline $\begin{array}{c}\text { Developmental } \\
\text { stages }\end{array}$ & wOP $(\mathrm{psu})$ & hOP \\
\hline M2 & $950 \pm 0(32.2)$ & $952 \pm 5$ \\
PL1 & $924 \pm 5 \mathrm{e}^{-6}(31.4)$ & $925 \pm 4$ \\
PL2 & $903 \pm 0(30.7)$ & $777 \pm 9$ \\
PL4 & $866 \pm 0(29.4)$ & $920 \pm 8$ \\
PL15 & $980 \pm 7(32.2)$ & $899 \pm 17$ \\
J & $918 \pm 0(31.2)$ & $816 \pm 6$ \\
A & $891 \pm 0(30.3)$ & $850 \pm 25$ \\
\hline
\end{tabular}

